\title{
KNOWING (HOW IT IS) THAT P: DEGREES AND QUALITIES OF KNOWLEDGE
}

Stephen Hetherington*

SÍNTESE - Pode o conhecimento de uma dada verdade admitir gradações? Sim, de fato, segundo o gradualismo deste artigo. $\mathrm{O}$ artigo introduz o conceito do saber-como que $p$ - isto é, o conceito de saber como é que $p$. Saber-como que $p$ é claramente gradual - admitindo gradações, dado que se pode saber mais ou menos como é que $p$. $\mathrm{E}$ a vinculação que este artigo faz entre sabercomo que $p$ e saber que $p$ revela que este último tipo de conhecimento também é gradual (mesmo que disfarçadamente). A teoria dos criadores-deverdade [truthmakers] é, então, invocada para enriquecer a análise, e a análise é aplicada às tarefas de fazer sentido do fundacionismo e de barrar uma certa forma de ceticismo.

PALAVRAS-CHAVE - Conhecimento. Gradualismo. Absolutismo. Ceticismo. Fundacionismo, Criadores-de-verdade.
ABSTRACT - Can knowledge of a particular truth admit of degrees? Indeed so, according to this paper's gradualism. The paper introduces the concept of how-knowledge that $p$ - that is, the concept of knowing how it is that $p$. Howknowledge that $p$ is clearly gradational admitting of degrees, as one can know more or less of how it is that $p$. And this paper's linking of how-knowledge that $p$ with knowledge that $p$ reveals the latter kind of knowledge, too, to be gradational (even if covertly so). Truthmaker theory is then called upon to enrich the analysis, and the analysis is applied to the tasks of understanding foundationalism and of thwarting one form of scepticism.

KEY WORDS - Knowledge. Gradualism. Absolutism. Scepticism. Foundationalism. Truthmakers.

This paper argues that we should accept a gradualism about knowledge that p - propositional knowledge. That sort of gradualism rejects knowledgeabsolutism, a thesis that has long been taken for granted within many epistemological debates. ${ }^{1}$ Even statements - let alone endorsements - of knowledgegradualism are almost entirely absent from epistemology. ${ }^{2}$ I will therefore allow my

* School of Philosophy - University of New South Wales.

For how long has that thesis helped to shape epistemology? Elsewhere (2006b), I argue that it seems to have been bequeathed by Descartes's eminently optional yet historically influential methodology.

2 In Good Knowledge, Bad Knowledge (2001), I present a detailed gradualism about propositional knowledge - a less generic knowledge-gradualism than this paper's. Unlike the knowledgegradualism in that earlier book, this new version will not be framed in terms of whatever strength of

\begin{tabular}{|l|l|l|l|l|l|}
\hline VERITAS & Porto Alegre & v. 50 & n. 4 & Dezembro 2005 & p. 129-152 \\
\hline
\end{tabular}


paper's knowledge-gradualism to take shape slowly, in accord with the sustained construction of the argument against knowledge-absolutism. I will be describing an aspect of knowledge that has been largely overlooked, along with some epistemological implications of rectifying that oversight.

\section{Introducing knowledge-absolutism}

It is epistemological orthodoxy that propositional knowledge is absolute, in the sense of being unable to admit of degrees or grades. Thus, I could never have some intermediate degree of knowledge that I have a hand - where this means that, at least in principle, tomorrow I could have a better degree of knowledge that I have a hand. Justification is gradational (epistemologists concede); knowledge is not (they insist). Evidence can be better or worse; knowledge cannot. The reason for this (epistemologists will say) is that knowledge is a threshold phenomenon. That is, once there is sufficient justification to make a true belief that $p$ knowledge, any further justification supporting that belief improves one's overall epistemic situation as regards $p$ - but without literally improving one's knowledge that $p$.

Yet none of that is really an argument for knowledge-absolutism. It is a statement of what knowledge is like if knowledge-absolutism is true. It articulates knowledge-absolutism's being true; it does not try to understand what knowledge would be like if knowledge-absolutism were not true. The standard acceptance of knowledge-absolutism remains, for most epistemologists, an unshakeable assumption. ${ }^{3}$ But must it be accepted at all, let alone so confidently? The next several sections argue directly against it. The result is a non-standard conception of knowledge - as subsequent sections will make clear, by applying it to a few traditional epistemological issues.

\section{How-knowledge that $p$ and non-absolutism}

My argument begins with the following question: Do I know how it is that I have two hands? ${ }^{4}$ Do I have that particular instance of how-knowledge (as we might call it)? If I do, this can occur in different ways and to different extents. After all, it is obvious that I do not know everything that happens to constitute my having hands. That is, I do not know fully or completely or exhaustively how it is that I have hands, because I do not know all of the constitutive aspects of my

justification is present within a given piece of knowledge. (It is possible that further argument could discover that this paper's generic gradualism would be most fruitfully instantiated by something like the earlier version. I will not determine that here.)

3 Few epistemologists have striven to argue for it. In (2001: 13-18), I discuss attempts by Ryle and by Dretske. Section 14 considers another way in which epistemologists might attempt to establish knowledge-absolutism.

4 This should not be confused with knowing how to do something, the latter being the distinctively Rylean (1949: ch. 2) sense of knowing how. On links between knowledge-that and knowing-howto, see my (2006a). 
having hands. I do not know in its constitutive entirety whatever it is that amounts to my having those hands. I do not know all of what it takes for me to have hands - all that there is to my having them. In short, I do not know fully how it is that I have hands.

Do I therefore lack knowledge of how it is that I have hands? I do not know many details of how the tendons, veins, and so on, are arranged or how they function within my hands. It is true that I am ignorant of those aspects of whatever it is that constitutes the entirety of my having these hands. Am I ignorant of too many such aspects?

That is the question - when generalised - of whether we should be sceptics about how-knowledge. In reply, we should concede that even at best I possess lessthan-exhaustive knowledge of how it is that I have hands. This might not be a failing, though. There is a real possibility that all how-knowledge is less-thanexhaustive, given the normal conceptual and computational finitude among people in general. And (unless scepticism is accepted independently) we are not obliged to infer from this that there is no how-knowledge.

What we should infer is a non-absolutism about any how-knowledge of ours. That is, instances of how-knowledge admit of degrees or grades. I can know more or less fully, in more or less detail, how it is that I have hands - thereby having a congruent degree or grade of knowledge of how it is that I have hands. Even if it is impossible to know exhaustively how it is that I have hands, ${ }^{5}$ there are various lesser reaches which such knowledge might have.

Here is one potential explication of the basic idea behind that suggested nonabsolutism about how-knowledge:

Hk At time $t$, a person $x$ 's how-knowledge that $p$ is more, or it is less, well developed or extensive, in accord with however many aspects of how it is that $p$ which are known by $x$ at $t^{6}$

Manifestly, that $p$ obtains is one of those aspects of how it is that $p$; it is a minimal aspect. But in practise it is usual for people to know many further aspects, too, of how it is that $p$ - whenever, of course, they have the how-knowledge that $p$ at all. Standardly, whatever how-knowledge is present in practise is better developed or extensive than in principle it might have been. The extent to which a particular piece of how-knowledge is developed may (roughly speaking) be regarded as a measure of the epistemic richness or depth of that how-knowledge.

5 I am not committing myself to exhaustive how-knowledge's never being available (although section 9 will take that possibility seriously). If there is little structural complexity in how it is that $p$ (for a particular $p$ ), maybe there can be exhaustive knowledge of how it is that $p$

6 Here are two possible variations on this initial suggestion (neither of which I will develop in this paper). (1) Chuck Cross suggested to me that one instance, $k_{1}$, of how-knowledge that $p$ is more extensive than a second one, $\mathrm{k}_{2}$, if the set of aspects of how it is that $p$ which $\mathrm{k}_{1}$ encompasses properly includes the set of aspects of how it is that $p$ which $k_{2}$ encompasses. On this variation (as Cross acknowledged, approvingly), not all instances of how-knowledge that $p$ possess comparable degrees of extensiveness - because the described relationship of proper inclusion is not always present. (2) We might incorporate within Hk a weighting for the centrality, to how it is that $p$, of the various known aspects of how it is that $p$. Would this weighting be pragmatic? 


\section{Knowledge that $p$ entails how-knowledge that $p$}

Section 2 has conveyed some sense of the structure of any case of howknowledge. ${ }^{7}$ Now let us turn to the relationship between how-knowledge that $p$ and knowledge that $p$. I believe that $\rightarrow \mathrm{H}$ is true:

$\rightarrow \mathrm{H} \quad$ Knowing that $p$ entails having how-knowledge that $p$. More fully: At time $t$, if a person $x$ knows that $p$, then at $t x$ has how-knowledge that $p$ (where this howknowledge has some degree $d$ of development or extensiveness). For short: $\mathrm{K}(p) \rightarrow(\exists d)_{d} \mathrm{~K}_{\mathrm{H}}(p)$.

$\rightarrow \mathrm{H}$ allows for your having a comparatively superficial case of knowledge that $p$ - where that superficiality is epistemic. You would know only superficially how it is that $p$. This would be your knowing less extensively how it is that $p$ - less extensively than is realistically and normally possible. More formally: You would know that $p$, without knowing that $q$ - for many instances of $q$ (where $q$ is an aspect of how it is that $p$ ).

The same is true, mutatis mutandis, of your having an epistemically deeper instance of knowledge that $p$. You would know more deeply how it is that $p$. This would be your knowing more extensively how it is that $p$ - more extensively, perhaps, than is normal. More formally: There would be fewer instances of $q$ (where $q$ is an aspect of how it is that $p$ ), such that you know that $p$ without knowing that $q$.

For instance (with all else being equal), if I were a surgeon, I would know - as I do now - that I have two hands. But in doing so, I would know more fully than I do now how it is that I have them. In different respects, the same would be true if I were an evolutionary biologist. In each case, I would know more aspects than in fact I do of how it is that I have hands. This further knowledge might be part of the respective bodies of evidence I would possess in those cases (as a surgeon or an evolutionary biologist) for the belief that I have hands; then again, it might not. In either event, the further knowledge would be present - thereby enriching those imagined ways in which I would know that I have hands. I am not saying that (within those hypothesised cases) the belief that I have hands would be knowledge in the first place only because of the existence of those larger networks of related knowledge. ${ }^{8}$ Nevertheless, in each case that belief is enriched epistemically, as the knowledge it is, by its degree of embeddedness within the respective case's network of pieces of knowledge of aspects of how it is that I have hands. The knowledge that I have hands is enriched to some more or less specific degree, by being embedded within a given - and more or less extensive - network. Each of those actual or hypothetical instances of knowledge that I have hands thus includes a degree of development some degree of wider-ranging epistemic embeddedness - in its grasp of how it is that I have hands.

For more on the locution, 'knows how it is that', see Franklin (1981: 201-8).

This paper offers no reductive definitions (in terms of phenomena other than knowledge that $p$ ) either of knowledge that $p$ or of how-knowledge that $p$. My main goal is to chart structural links between knowledge that $p$ - whatever that is, more precisely (something I leave open) - and howknowledge that $p$. Section 9 presents my most detailed charting of those links. 


\section{How-knowledge that $\boldsymbol{p}$ entails knowledge that $\boldsymbol{p}$}

The converse entailment to section 3's core thesis, $\rightarrow \mathrm{H}$, also obtains:

$\mathrm{H} \rightarrow \quad(\exists d)_{d} \mathrm{~K}_{\mathrm{H}}(p) \rightarrow \mathrm{K}(p)$

This says that if one has even some degree of how-knowledge that $p$, one has knowledge that $p$. No matter whether one's how-knowledge that $p$ is epistemically deeper (in section 3's sense of being more fully or extensively developed), or whether it is epistemically shallower (in section 3's sense of being less fully or extensively developed), one thereby knows that $p$. Trivially, $\mathrm{H} \rightarrow$ is true because (as section 2 observed) a minimal part of how-knowing that $p$ is one's knowing that $p$. A fortiori, $\mathrm{H} \rightarrow$ is true of the usual - more substantive, non-minimal cases.

Thus, if I were a surgeon, I would possess quite epistemically rich or deep significantly more extensive - knowledge of how it is that I have two hands; and obviously this how-knowledge would include the knowledge that I have them. As it is, I possess epistemically poorer - more superficial, less extensive knowledge of how it is that I have hands. Part of even this how-knowledge, though, is my knowing simpliciter that I have hands. The degree of the hypothesised how-knowledge that I have hands (how-knowledge I would have as a surgeon) is higher than the degree of my actual how-knowledge that I have hands. Nevertheless, in each case I would know that I have hands - as part of knowing how it is that I have hands.

\section{Knowledge that $p$ is how-knowledge that $p$}

Section 3's $\rightarrow \mathrm{H}$ and section 4's $\mathrm{H} \rightarrow$ may be conjoined to give us this equivalence:

Knowing that $p$ both entails, and is entailed by, having some quality or degree of how-knowledge that $p$.

Here is a fuller rendering of that equivalence:

$\leftrightarrow \mathrm{H} \quad$ A person $x$ 's knowing on a particular occasion that $p$ both entails, and is ntailed by, $x$ 's having some quality or degree on that occasion of how-knowledge that $p$. For short: At $t, \mathrm{~K}(p) \leftrightarrow$ At $t,(\exists d)_{d} \mathrm{~K}_{\mathrm{H}}(p)$.

\section{Knowledge that $p$ and non-absolutism}

How-knowledge that $p$ is clearly gradational, admitting of degrees. Hence, if $\leftrightarrow \mathrm{H}$ is true, then knowledge that $p$ has that same structural feature. Each instance of knowledge that $p$ is thereby an instance of how-knowledge - howknowing to some or other degree $d$ - that $p$.

Today, I have a less well developed or extensive instance of knowledge of how it is that $h$ (where $h$ is the proposition that I have two hands). However, suppose that I will spend the next ten years studying human anatomy and biol- 
ogy. In ten years time, I will continue knowing how it is that $h$ - but I will do this more fully or extensively, with my store of associated knowledge having grown in the meantime. It is clear (via the following reasoning) why that disparity between the respective degrees or qualities of those two instances of howknowledge is a disparity between degrees or qualities of instances of knowledge simpliciter:

(1) Given $\leftrightarrow H$, my present knowledge that $h$ is how-knowledge that $h$. (2) Given $\leftrightarrow H$, the knowledge that $h$ which I will have in ten years time (after much study of human anatomy and biology) will be distinct how-knowledge that $h$ from that which I now have. (3) Indeed (given all of that study), my later how-knowledge that $h$ will possess a higher quality or degree than does my present how-knowledge that $h$. (4) So, by that same token, my later knowledge that $h$ will possess a higher quality or degree than does my present knowledge that $h$.

Along such lines, therefore, $\leftrightarrow \mathrm{H}$ implies this:

${ }_{d} \mathrm{~K} \quad$ The quality or degree of a person $x$ 's how-knowledge at time $t$ that $p$ is the quality or degree of $x$ 's knowledge at $t$ that $p$.

From $\leftrightarrow \mathrm{H}, x^{\prime}$ 's knowledge at $t$ that $p$ amounts to $x$ 's how-knowledge at $t$ that $p$. The quality or degree of the latter is thereby the quality or degree of the former as ${ }_{d} \mathrm{~K}$ says. Thus, we gain a non-absolutism about knowledge that $p$.

Is that non-absolutism epistemologically threatening? I do not believe so. As is standardly acknowledged, many - maybe all - other kinds of knowledge are avowedly non-absolutist. For example, we recognise that there may be stronger or weaker knowledge of an object or a person or a topic. We are relaxed about the fact that there can be more or less well developed knowledge-who, knowledge-how, knowledge-why, and so on. Now we discover knowledge-that's being no different in this respect. That result should be welcomed, as constituting a step towards increased epistemological unification and greater theoretical simplicity. It is a result worth having, if indeed we may have it. ${ }^{9}$

Is it unprecedented? Sometimes contextualism is said to be a non-absolutist thesis. But it is not endorsing the sort of non-absolutism articulated via ${ }_{d} \mathrm{~K}$ in section 6 . Or, equivalently, ${ }_{d} \mathrm{~K}$ is not a contextualist thesis, as contextualism is generally developed. Contextualists claim that attributions or denials of knowledge are true or false, relative to epistemic standards that can vary from one occasion of attribution or denial to another. However, contextualists require a constant underlying epistemic standard to be applied within each such context - the standard of all relevant or salient alternatives or possibilities being eliminated. And that standard is absolutist. It does not allow that there could be intermediate and differing degrees of knowledge that $p$ within a context - due to intermediate and differing numbers of alternatives being eliminated there, say. Lewis (1996: 562-3) is the only contextualist, I believe, who has embraced non-absolutism. (My account also differs from contextualism in not being first and foremost a semantic theory.) 


\section{Degrees of knowledge and degrees of belief ${ }^{10}$}

Let us now reflect upon degrees of belief. Here are two structural possibilities for how we might seek to understand that phenomenon:

db1 A person can have some degree of belief that $p$ without having a belief simpliciter that $p$.

db2 o have even some degree of belief that $p$ is to believe simpliciter that $p$.

On db1, someone can have a prior and partial degree of belief that $p$ - where this falls short of having a 'full' belief that $p$. Only a sufficiently high degree of belief would be a full belief - in effect, an actual belief. Only in that way would a belief as such be constituted. But in that respect db1 and db2 are significantly different. On db2, having a degree of belief that $p$ is not constitutively prior to having a belief per se that $p$; rather, it is a way for the latter - a belief that $p$ as such - to be present. Thus, on db2, within the category of belief simpliciter there can be gradations. There could be more or less intense and committed instances, say, of a belief that $p$, with these constituting stronger or weaker degrees of belief that $p$. Nonetheless, each instance would - in its own way - be a belief that $p$.

And db2 corresponds to my intended picture of the constitutive relationship between knowledge and how-knowledge. Analogously to db1 and db2, these two possible theses arise:

dk1 A person can have some degree of how-knowledge that $p$ without having knowledge simpliciter that $p$.

dk2 To have even some degree of how-knowledge that $p$ is to know simpliciter that p.

On dk1, someone can have a prior and partial degree of how-knowledge that $p$ where this falls short of having a 'full' instance of knowledge that $p$. Only a sufficiently high degree of how-knowledge would be a full instance of knowledge that $p$ - in effect, an actual case of knowledge that $p$. Only in that way would a piece of knowledge be constituted. But in that respect dk1 and dk2 are significantly different. On dk2, having a degree of how-knowledge that $p$ is not constitutively prior to having a case of knowledge per se that $p$; rather, it is a way for the latter to be present. Thus, on dk2, within the category of knowledge simpliciter that $p$ there can be gradations - with instances of how-knowledge that $p$ being more or less extensive, while remaining instances of knowledge that $p$.

Yet of what, more precisely, are these gradations constituted? Sections 2 through 6 have described a dimension along which these gradations can be manifested. Unlike the dimension most obviously alluded to by db2, the dimension underlying $\mathrm{dk} 2$ is not one of psychological commitment or intensity. It is purely epistemic. It might thereby be justificatory; then again, it might not be - a possi-

10 This section owes much to observations and questions by Chuck Cross. 
bility to which I will return in section $9 .{ }^{11}$ So far, this paper has allowed for both of those alternatives by describing the epistemic dimension in question simply as involving - generically - further knowledge. My proposal reminds us that, in knowing that $p$, one is likely to be knowing more than the unadorned truth that $p$. One knows more, or one knows less, of how it is that $p$ : one has a more, or a less, extensive instance of how-knowledge that $p$. Correlatively, one knows that $p$ with an associated epistemic depth or extensiveness. Each instance of knowledge that $p$ embodies some epistemic way in which the truth that $p$ is known. And there can be different such ways, more or less epistemically deep or extensive ways. These characterise the respective instances of knowledge that $p$. How one knows that $p$, on a given occasion, is in part the extent to which one knows how it is that $p$. This is an extent to which one has taken, or extended, one's knowledge that $p$.

As things stand, for example, I know that I have two hands. I do so in such a way as to possess some degree $d$ of how-knowledge that I have hands, knowing as I do various aspects of how it is that I have them. But if, instead, I were to possess a surgeon's form of knowledge that I have hands, then I would probably possess this knowledge in such a way as to have some degree $d+$ of howknowledge that I have hands - where $d^{+}>d$. Other things being equal, I would know more aspects of how it is that I have hands. There is, it seems, this roughly measurable difference between these ways for me to know the truth of my having hands. $^{12}$

\section{How-knowledge that $p$ and truthmakers}

We have found knowledge that $p$ to be how-knowledge that $p$ - which is knowledge of various aspects of how it is that $p$. Presumably, therefore, to have how-knowledge that $p$ is to have knowledge of various aspects of a truth - that$p^{13}$ Which aspects, though? Truthmaker theory can help us here. I will focus on Armstrong's (2004) recent version of truthmaker theory. ${ }^{14}$

11 My (2001) explicates this epistemic dimension in justificatory terms. There, I propose that an instance of knowledge that $p$ is better or worse as knowledge that $p$, in accord with the strength of whatever justification (if any) it includes. Note 2 explained how this paper's account is more general than that - not relying upon knowledge's having to include justification at all. (And see note 18 below.)

12 It might seem that I am arguing for knowledge that p's being a kind of understanding. I would indeed welcome that development of my theory, but I am not relying upon it. Presumably, the idea is that any how-knowledge that $p$ - and hence, given $\leftrightarrow \mathrm{H}$, each associated instance of knowledge that $p$ - is an instance of more or less extensive understanding of how it is that $p$. Few epistemologists discuss understanding. Two exceptions are Zagzebski (2001) and Elgin (2006) - who believe that knowledge is quite different from understanding. The proposed development of my theory would disagree with them about that.

13 This does not entail that the knowledge that $p$ would be knowledge that some particular sentence or proposition, say, is true. Knowledge that $p$ could be knowledge of a truth without being knowledge that something is true.

14 My page references in this section are to Armstrong's book. For more on the concept of a truthmaker, see Rodriguez-Pereyra (2002: 31-40). 
Truthmaker Maximalism (p. 5) says that any truth has a truthmaker. Knowledge is routinely taken to be knowledge of a truth. So, knowledge is of something which has a truthmaker. Given Truthmaker Necessitarianism (ibid.), that truthmaker is something in the world that necessitates that truth's being true. Now, truthmakers can be more or less discerning (p. 18). The world as a whole is the least discerning truthmaker of all, and one's knowing that $p$ is rarely one's knowing the world as a whole. Consider, though, the concept of a minimal truthmaker (pp. 19-21). If a truthmaker for a truth that $p$ is minimal, then to 'subtract' ( $p$. 19) some part of it is to be left with something that does not make it true that $p$. A minimal truthmaker for the truth that Smith is male, for example, is Smith's being male. But there are many further aspects to, or parts of, Smith's being male. Armstrong would say that it is composed (non-mereologically) of a universal - namely, the property of being male - and a particular - namely, Smith. Armstrong would then expect science to reveal the underlying natures of those parts of the world. Physical constituents, biological functions, nomically constitutive tendencies, and so on, would be uncovered. (Maybe there would be more, such as socially constituted normative aspects to being male.)

In any case, section 2's guiding description, Hk, of how-knowledge can be parsed somewhat more precisely, in terms of truthmakers:

HkTm At time $t$, a person $x^{\prime}$ s how-knowledge that $p$ is more, or it is less, well developed or extensive, in accord with how many parts of a minimal truthmaker for $p$ are known by $x$ at $t .^{15}$

Here are a few clarificatory details about HkTm.

(i) In knowing parts of a minimal truthmaker for $p$, one can be knowing what are also minimal truthmakers for other truths. (Smith's being male is a minimal truthmaker for the truth that Smith is male - while being only a proper part of a minimal truthmaker for the truth that Smith is male and a philosopher.) Thus, components of an instance of how-knowledge can themselves be instances of propositional knowledge. ${ }^{16}$

(ii) Armstrong accepts (pp. 17-19) that truthmakers can include truthmakers as parts, even for the same truth. That is not true of minimal truthmakers. But if $\mathrm{H} \rightarrow$ (and thereby $\leftrightarrow \mathrm{H}$ ) is to be true, we need to understand HkTm so that part of a minimal truthmaker for $p$ is that minimal truthmaker itself. (Otherwise, howknowledge that $p$ will be precluded from including knowledge that $p$ - because the latter knowledge would not be knowledge of a minimal truthmaker for $p$.) This is easily done. We need only permit HkTm's talk of parts to cover both proper and

15 I say 'a minimal truthmaker', rather than 'the minimal truthmaker', because not all truths have only one minimal truthmaker (p. 21). For that same reason, HkTm could be formulated so as to allow the degree of $x$ 's how-knowledge that $p$ to reflect $x$ 's knowing (parts of) more than one minimal truthmaker for $p$.

16 In principle, though, not all of them need be. I leave open the possibility of one's knowledge of how it is that $p$ including, for example, knowledge - including non-propositional knowledge - of a nonpropositional individual such as Smith or such as parts of a hand. But this sort of possibility - although it is significant for any integrated theory of forms of knowledge (an ideal mentioned briefly at the end of section 6) - plays no role in the rest of this paper. 
improper parts - while noting that the minimal truthmaker is a part, without being a proper part, of itself. (And knowing the minimal truthmaker will not entail knowing every other part of it. $)^{17}$

(iii) One possibility worth examining (but which I have not required in HkTm) is that how-knowledge that $p$ should include some knowledge of how the aspects of how it is that $p$ constitute its being the case that $p$. Such knowledge might 'bind' the other pieces of knowledge. There would be more or less well developed knowledge of how $p$ is constituted by, or constructed from, these various aspects.

\section{Knowledge that $p$ and gradualism}

HkTm explicates how-knowledge in terms of minimal truthmakers. Given $\leftrightarrow \mathrm{H}$ and ${ }_{a} \mathrm{~K}$, that explication should spawn a related account of knowledge simpliciter. So, here is how we might understand the range of possible degrees and qualities of knowledge simpliciter in terms of minimal truthmakers: ${ }^{18}$

(1) Base clause

(i) Degrees. When a person X's how-knowledge that $p$ is restricted to knowing a minimal truthmaker for $p, x$ has minimal knowledge that $p: x$ would have the lowest degree of how-knowledge that $p$ - and thereby of knowledge that $p$. (ii) Qualities. When $x$ has minimal knowledge that $p, x$ knows that $p$ in a bare way. ${ }^{19}$ We might regard this as being the poorest or narrowest possible knowledge that $p$, because there is nothing less that $x$ could know while still knowing that $p$.

17 It might be objected (as follows) that HkTm does not explain how one could know a disjunction, say, without knowing either disjunct individually:

A truthmaker for a disjunction which is not a truthmaker for one of the disjuncts is not a minimal truthmaker for the disjunction. Consequently, in knowing the disjunction by knowing a minimal truthmaker for it, one has to know at least one of the individual disjuncts.

But that depends on how a truthmaker's parts are identified. Recall that, for Armstrong, a minimal truthmaker for $p$ is one from which no part can be subtracted, without its ceasing to be a truthmaker for $p$. I suggest our restricting the relevant concept of a (proper) part to a conjunctive part. Then there can be a minimal truthmaker for a disjunction that is not a minimal truthmaker for one of the disjuncts. We may continue regarding one's knowledge of a disjunction as able to be knowledge of a minimal truthmaker - without its having to include knowledge of a disjunct. (The same is true, mutatis mutandis, of knowledge of conditionals, existential generalisations, and so on.)

18 The present account differs from my earlier (2001) analysis in utilising truthmaker theory. Another difference is the present account's being non-reductive (as note 8 observed). It allows structurings of pieces of knowledge to accomplish what I previously explicated via strengths of justification. (This difference will be more apparent in section 12.) That is, in my previous knowledgegradualism, the degree or quality of a piece of knowledge was a function of what constituted the knowledge 'from within' - the strength of its justificatory component. In this paper's knowledgegradualism, the degree or quality of a piece of knowledge that $p$ is a function of the extensiveness of the 'wider' network of knowledge that constitutes the degree to which the knowledge that $p$ how-knows that $p$. (Compare this form of theory with Foley's [1996] analysis. Reductively, he sees knowledge as being a true belief embedded within a wider array of true beliefs. But he remains absolutist, not noticing the gradualist potential in his account. That potential is present because the wider array of true beliefs can be more or less wide.)

19 In using the term 'bare', I have in mind the metaphysical analogy of a bare particular. One would know that $p$ without knowing any further aspects of how it is that $p$. This is like knowing a particular without knowing any of its properties. 
For example, if I learn by rote, from a reliable source, that the earth orbits the sun (call this truth e), I know that e. But if I know no further aspects of how it is that e, my knowledge that $e$ is the only knowledge I have of how it is that e. So, my knowledge that $e$ is correlatively minimal in degree. It is a bare case of knowledge that e. I could not lose any part of that knowledge without losing the entire knowledge that $e$.

(2) Inductive clause

(i) Degrees. To the extent that $x$ 's how-knowledge that $p$ includes knowledge of further parts of a minimal truthmaker for $p, x$ has knowledge simpliciter that $p$ which is correlatively more developed: $x$ has that-much-higher-than-minimal a degree of how-knowledge that $p$ - and thereby of knowledge that $p$. (ii) Qualities. To the extent that $x$ has knowledge that $p$ which is more developed, $x$ has correspondingly broader or better or richer knowledge that $p$. To the extent that the knowledge that $p$ is developed, it includes knowledge of more aspects of how it is that $p$. Any of this further knowledge of aspects of how it is that $p$ is knowledge which $x$ could lose before knowledge that $p$ would have departed (all else being equal).

Suppose that I begin studying astronomy, and that I start knowing more aspects of how it is that e (where again this is the truth that the earth orbits the sun). This would improve my knowledge that e: I would be broadening and enriching my knowledge that e. I would continue knowing that e; now, though, I would know it in a qualitatively different way. Even in knowing that e, I would be knowing more than I might have done. Certainly, even in still knowing that e, I would be knowing more than I formerly did. We may think of the situation in the following way: I could awaken every day for many days - having lost, with each new day, one more piece of my recently acquired astronomical knowledge - before returning to knowing only barely that $e$.

In some such way, a basic non-absolutism about knowledge becomes a more detailed gradualism about knowledge. There is a range of possible degrees and qualities of knowledge that $p$. That range has a lower bound - a lowest possible degree and quality of knowledge that $p$. I have not committed myself to there being a highest such degree. This is because there could often - maybe always - be infinitely many aspects to how it is that $p$. In such cases, presumably, complete or maximal knowledge that $p$ is impossible. That would be knowledge of every aspect of how it is that $p$; and when there are infinitely many of those aspects, any occasion of knowing that $p$ leaves some of them unknown. On these occasions, $p$ would be known to a degree less than 1 . The knowledge that $p$ would possess an intermediate quality. I am not saying that in fact there are no cases of maximal or complete knowledge that $p$ - instances of knowing that $p$ to degree 1. Maybe there are none; maybe there are some. I suspect that these will be rare, even at best. 


\section{Gradualism's central concept}

That suspicion should constrain how we are to understand gradualism's central concept. We should not presume that better knowledge that $p$ is closer to the end-point of being complete or maximal knowledge that $p$. As section 9's final paragraph implies, there might be no such end-point (for most, perhaps all, values of ' $p$ '). This could be so, even in cases where we wish to distinguish better from worse knowledge that $p$. A surgeon examining me knows better than I do that $h$ (that is, that I have hands). This is so, even if there are infinitely many aspects of how it is that $h$ - which would imply that neither of us could possess complete knowledge that $h$.

So, we need an alternative explication of the phenomenon of better or worse knowledge that $p$. Here is mine: Knowledge that $p$ is better as knowledge that $p$ insofar as it is further from the starting-point of being bare or minimal knowledge that $p$. Correlatively (and roughly), we might endorse something like this:

One piece of knowledge that $p$ is better than another (all else being equal) when the

former knows $n+1$, while the other knows only $n$, aspects of how it is that $p$.

In effect, we are explicating the degree or quality of any instance of knowledge that $p$ in terms of how much better it is than it could have been as knowledge that $p$ - rather than in terms of how close it is to, or how far short it is of, being what would be an ideal way for it to be as knowledge that $p$.

This distinction has substantive implications. For example, sceptics describe what could be thought of as being ideal - and what would clearly be temptingly good - ways in which to know that $p$. Sceptics do this, en route to claiming that people's beliefs always fall short of those attainments. But the interpretive distinction introduced just now suggests that sceptics could be framing the debate so as to favour their sceptical conclusions from the outset. They conceive of knowing as a matter of how well one has done, in terms of canonical progress towards an endpoint. The present section advocates an alternative conception of knowing - as a matter of how well one has done, in terms of canonical progress away from a beginning-point. One could have made good progress, relative to a beginningpoint - even if one has not made good progress, relative to an end-point (especially if there is no such end-point). The potential for a sceptical interpretation is manifest in the latter model..$^{20}$

\section{Can there be minimal knowledge?}

If section 10 is right, then section 9's concept of bare or minimal knowledge plays a vital role within gradualism. It describes the beginning-point, in relation to which any instance of knowledge that $p$ is however good it is as knowledge that $p$ - by being more or less far from or beyond being minimal knowledge that $p$. Yet

20 Section 13 returns to this issue, by providing details of how this conceptual reorientation undermines some scepticisms about knowledge. 
we need to confront the possibility that there cannot be any bare or minimal knowledge that $p$. Is the concept of such knowledge empty, even necessarily so? If it is, then section 10's account of better or worse knowledge that $p$ is also empty. Is this a danger?

We might at first think so. Even to know just that an individual a has a feature $F$ could be thought to require knowledge of what, more generally, it is to be $F^{21}{ }^{2}$ This further knowledge would be of an aspect of how it is that a is $F$ - rather than of how it is that a is $H$ (for some contrary property $H$ ). Accordingly, there would be better developed how-knowledge that a is $F$. There would be extra how-knowledge that a is $F$, beyond the knowledge merely of the truth that a is $F$. So, the knowledge that a is $F$ which is present would not be bare knowledge that a is $F$.

Still, even that further knowledge might not be needed as part of knowing that $a$ is $F$. Imagine not knowing anything about the property $F$ - what it is to be $F$ - other than that a has that property. You know that a is $F$; in doing so, you know that $F$ is possessed by a. Suppose that this is your entire knowledge about a and about F. On Armstrong's favoured conception (pp. 47-8) of instantiation, there is an (at least) partial identity between a particular instantiating a property and the property being instantiated. On this conception, it is possible to know that a is $F$ without knowing anything of $F$ beyond its being instantiated by a. You might know as little of $F$ as of a; you might have this knowledge of each at the one time. ${ }^{22}$ I am not arguing that any actual knowledge that a is $F$ is like that - minimal or bare. But could there be some?

Moreover, the concept of minimal knowledge is one of which at least a little intuitive sense can be made. Regardless of whether anyone ever has minimal knowledge, it would be knowledge lacking several features we wish most, perhaps all, of our knowledge to possess. For minimal knowledge that $p$ involves no developed understanding of how it is that $p$. It includes no insights into how it is that $p$. It is unilluminating as to what it is for $p$ to obtain. All of this is so, because minimal knowledge that $p$ is unaccompanied by knowledge of any parts of a

21 Evans would have said so, courtesy of his Generality Constraint (1982: 100-5, 256). (I am grateful to Anne Newstead for alerting me to Evans's views on this.) Thus, in being able to think of a as being $F$, one must be able to think of a as being $G$, as being $H$, and so on. Evans also said that one needs to be able to think of other individuals - $b, c$, and so forth - as being $F$. Nonetheless, even if Evans is right about what it is to think that a is $F$, no analogous constraint applies to knowing that $a$ is $F$. First, knowing that it is true that $a$ is $F$ does not require its being true (let alone its being known to be true) that a is $G$ or that $a$ is $H$, or that $b$ is $F$ or that $c$ is $F$. Moreover, even if further knowledge is required, it need only be knowledge of conceptual possibilities (what it is for a to be $G$, say, if a is $G$ ) - not knowledge of actualities, let alone ones which are constitutively part of a's being $F$. Knowing how it is that a is $F$ does not entail knowing how the world could be in ways (such as a's being $G$ or b's being $F$ ) that would structurally overlap with a's being $F$. (The same is true of the knowledge's putative belief component. Even if the knowledge of a's being $F$ involves a belief that a is $F$, it does not thereby involve a belief that $a$ is $G$ or that $b$ is $F$. At most, beliefs about associated possibilities are implicated.)

22 Your knowledge of each would not rule out a's being the only instance of $F$, just as it would not rule out $F$ being a's only property. Would your knowledge therefore be leaving open the possibility of the identity between $a$ and $F$ being total, not merely partial? (Is that a possibility?) 
minimal truthmaker for $p$ - any parts beyond $p$ itself. Can knowledge be like this, at least in principle? Seemingly, yes. When I write of some possible knowledge's lacking those further features, I am confident of being understood, if only in a less developed way. To at least that extent, therefore, we may coherently distinguish between knowledge which is, and knowledge which is not, impressive in these further ways. ${ }^{23}$

\section{Minimal knowledge as foundational knowledge}

How unimpressive is minimal knowledge? For example, is it mere true belief - a true belief bereft of any justificatory support? I am not presuming so. ${ }^{24}$ Hence, I am explicating its minimality or bareness in terms of its object (namely, $p$ - and nothing else), rather than in terms of an absence of justificatory support for it. I will continue leaving open that question of whether cases of minimal knowledge enjoy justificatory support. And in this section I will explicate the minimality or bareness of such knowledge along a different dimension, one that is compatible with the presence of justification (even if not - as we will soon find - of all kinds of justification). I will show how we may understand minimal knowledge as a form of foundational knowledge.

This will involve my offering a slightly non-standard conception of foundational knowledge. As it is standardly defined, foundational knowledge is noninferential knowledge. It is knowledge from which (even if only via rational reconstruction) all inferential knowledge ultimately arises. How should we understand inferential knowledge in itself? Typically, epistemologists deem inferential knowledge that $p$ - non-foundational knowledge - to be present only if some further (and prior) knowledge that $q$, from which the knowledge that $p$ has arisen, is providing sufficient epistemic support for the truth of the belief that $p$.

But we may combine that standard picture with this paper's model of knowledge. Because the prior knowledge that $q$ is either actual or implicit evidence for $p$, it is knowledge of an aspect of how it is that $p$. (By being evidence for $p$, it is not $p$ itself - that is, $p$ reappearing. It is some other truth, revealing part of what is involved in how it is that $p$.) Accordingly, that evidence might well be knowledge of a proper part of a minimal truthmaker for $p$. In knowing that all Gs are Fs, say, one might partly base that knowledge upon knowledge that some specified particulars are both $G$ and $F$. And in knowing that one particular, $a$, is $F$, this could be partly based on knowledge that a is $G$ - where how it is that $a$ is $F$ is, in part, a's being $G$.

23 Whether any of our actual knowledge fails to be impressive in those ways is another matter, as is the question of whether we would be content with such knowledge. I do not attempt to resolve these matters in this paper.

24 In (2001), I use the term 'minimal knowledge' in that way. But (as note 2 indicated) this paper's account is more general. 
In such ways, inferential knowledge that $p$ becomes how-knowledge that $p$; and it becomes how-knowledge that $p$ which is more than minimal. It includes some developed understanding of how it is that $p$. It contains partial insight into how it is that $p$. It is somewhat illuminating as to how it is that $p$. In short, inferential knowledge possesses these features that we usually want in our knowledge that $p$ - features that (as section 11 explained) bare or minimal knowledge distinctively lacks. Inferential knowledge that $p$ is (in section 9's sense) more developed knowledge of how it is that $p$. It is a higher degree of knowledge that $p$. In that way, it is better knowledge that $p$.

In contrast, non-inferential knowledge is minimal or bare knowledge. That makes it perfect for playing the role of foundational knowledge. This need not be because it is certain or infallible (these properties having often been demanded of foundational knowledge). Nor need minimal knowledge's suitability for being foundational knowledge be because it includes only a slight amount of justification. I have said nothing about how much justification minimal knowledge includes. I have shown merely why it is not inferentially justified. Foundational knowledge, as characterised in this section, is subject to this constraint:

A piece of foundational knowledge needs only to be an instance of knowledge that $p$ which is not informative (and draws upon no information) about anything other than $p$.

That is precisely what minimal or bare knowledge that $p$ would be like. It would be knowledge - of one unadorned truth, of no other truths.

Admittedly, 'normal' or 'everyday' or standard knowledge that $p$ is not like that - minimal, bare. In most settings, knowing that $p$ includes knowing (even if, at times, only implicitly) more truths than $p$ alone. Normally, you know that $p$ by knowing additional aspects of how it is that $p$. But this is because usual instances of knowledge that $p$ are cases of non-foundational knowledge that $p$. Each is knowledge of more about $p$ - further aspects of how it is that $p$ - than the unadorned fact that $p$. In that sense, there is an inferential richness to most cases of knowledge. Correlatively, foundational knowledge that $p$ is not our usual knowledge that $p$. The marked majority of our instances of knowledge are not foundational - which is as it should be. (Maybe none are; I leave this open.)

What is less familiar is the picture being painted here of the nature (as against the extent) of foundational knowledge. I am generalizing the traditional concept of a foundationalist structuring of knowledge. On that traditional concept, pieces of knowledge located lower in, or at the base of, the structure inferentially support pieces of knowledge higher in the structure. But once we accept knowledgegradualism, that generic description may include this possibility:

Knowledge that $p$ could appear in more than one place within a foundationalist structuring, so long as different degrees or qualities of knowledge that $p$ are doing so. 
For example, once minimal knowledge that $p$ is at the base of a particular structuring, improved or better knowledge that $p$ might appear later in that structuring. Within a foundationalist structuring as it is traditionally conceived, any such reappearance of knowledge that $p$ is viciously circular (and hence is not permitted, insofar as the structuring includes only cases of real justification). Vicious circularity is present because that traditional conception of foundationalist structurings is also absolutist. On that conception, no reoccurrence of knowledge that $p$ can involve a different strength of knowledge that $p$. The traditional conception has to say that, whenever two instances of knowledge that $p$ appear within a foundationalist structuring, what is happening is this:

Knowledge that $p$ simpliciter is inferentially grounding knowledge that $p$ simpliciter - which is mere circularity.

But gradualism can interpret the reappearance of knowledge that $p$ within the one foundationalist structuring along these lines:

A lesser degree of knowledge that $p$ has been supplemented by knowledge of further aspects of how it is that $p$. The result is a more developed piece of how-knowledge that $p$. This amounts to an improved case of knowledge simpliciter that $p$. (And there is no vicious circularity in that epistemic improvement.)

Imagine having learnt that $p$ by rote, without understanding anything beyond the bare fact that $p$. This would be foundational - minimal - knowledge that $p$ for you. ${ }^{25}$ If you proceed to learn more aspects of how it is that $p$, your minimal knowledge that $p$ (involving as narrow a grasp of $p$ as is conceptually possible) becomes broader, enriched, thickened. Initially, your minimal knowledge that $p$ gives way to all-but-minimal knowledge that $p$. This includes your having at least a shred of understanding of how it is that $p$. Then slightly better knowledge that $p$ arrives, with its slightly improved understanding of how it is that $p$; and this kind of improvement might continue, with each improved piece of knowledge that $p$ being grounded partly upon the prior, less developed, piece of knowledge that $p$.

Of course, minimal knowledge that $p$ need not ground only improved knowledge that $p$ (in the gradualist way explained just now). It might lead to some more or less good knowledge that $q(q \neq p)$, which gives rise to some more or less good knowledge that $r(q \neq p \neq r)$, and so on. This would be a standard foundationalist structuring, with no proposition - $p, q, r$, and the rest - being known more than once within the structuring. Structurings like this have traditionally suggested the metaphorical description of foundational knowledge as standing to inferential knowledge much as the roots of a tree stand to the rest of the tree.

But the present section reveals additional potential complexity within the metaphor of a tree-structuring. That metaphor can accommodate the new

25 Traditional foundationalists say that in principle only a limited range of possible contents (such as immediately sensory ones) could be foundationally known. Williams (2001) argues strongly against restricting possible foundations in that way. Accordingly, I am not doing so. 
gradualist possibility - of there being cases where foundational knowledge that $p$ underwrites a structure incorporating more highly developed knowledge that $p$. Within those cases (we may now say), foundational knowledge that $p$ stands to the rest of the tree as the tree qua sapling stands to the comparatively mature tree. For in those cases the rest of the tree includes richer knowledge that $p$, along with minimal knowledge that $p$; and richer knowledge that $p$ amounts to being knowledge that $p$ which includes minimal knowledge that $p$ as a proper part of it. We may therefore think of this minimal knowledge that $p$ as being at the tree's core, rather than just at its base. The tree not only grows upwards; it grows outwards. It thickens. It adds layers. A thinner tree becomes a stronger tree. And foundational knowledge that $p$ can be part of an analogous process. It might be knowledge that $p$ around which some inferentially complex knowledge that $p$ has accumulated - like the rings of a tree. A sapling of knowledge that $p$ could give rise to a sturdy tree of knowledge that $p$. That is the (gradualist) case in which foundational knowledge that $p$ has been absorbed within more complex knowledge that $p$, with further aspects of how it is that $p$ having become known. This process would have added to the foundational (bare, minimal) knowledge that $p$, so as to build up a more complex (developed, rich) body of knowledge, amounting to improved knowledge that $p$. A progressively broader 'tree trunk' would have developed, with the sapling having done what healthy saplings tend to do: it would have grown upwards and outwards. A foundationalist structuring of successively improved instances of knowledge that $p$ would have taken shape. ${ }^{26}$

\section{Gradualism and scepticism}

But can there be knowledge that $p$ in the first place? Or are sceptics right to deny us either all knowledge or some significant kinds of knowledge? If ever there are epistemological questions taking us dangerously close to immersion within an ancient and seemingly inescapable quagmire, it is those ones. Nonetheless, we can make progress here. In this section, I briefly indicate how knowledge-gradualism might undermine some sceptical challenges.

At the heart of any such challenge to your knowing that $p$ is your being expected to know that some given possibility $\mathrm{O}$ does not obtain. If you fail to know that not-O, then (according to these sceptics) you fail to know that $p$. That sort of claim by sceptics has attracted much epistemological comment over the past thirty or so years. ${ }^{27}$ Even so, my present argument does not engage with that epistemological literature. I will argue that the sceptics' demand succumbs to a fatal dilemma, one that is apparent only once we adopt knowledge-gradualism.

${ }^{26}$ For more on this idea, with a detailed case study - of G. E. Moore's famously claimed knowledge of his hand and of the external world - see my (2001: 169-78).

27 Much of this was sparked by Nozick's (1981: 197-210) denial of knowledge's being closed under known entailment. Nozick extended a way of thinking begun by Dretske (1970). 
We begin the dilemma thus: Either O's not obtaining is part of a minimal truthmaker for $p$, or it is not. We will consider each of these alternatives, in turn.

Horn1. Suppose that O's not obtaining is part of a minimal truthmaker for $p$. In that case, sceptics are asking you to know that some particular part - namely, not-O - of a minimal truthmaker for $p$ is present. For example, if you are to know that there is a frog in front of you, sceptics might expect you to know that there is at least some physical object in front of you. But knowledge-gradualism implies that, in general, having knowledge that $p$ does not require having a higher degree or quality of knowledge that $p$. There can be lesser knowledge that $p$. Accordingly, there could be parts of a minimal truthmaker for $p$ that are not known even as $p$ itself is known, even as a minimal truthmaker for $p$ is known. Given $\leftrightarrow \mathrm{H}, p$ could be known - even quite well - when some aspects of how it is that $p$ are nonetheless not known by that same person.

Presumably, sceptics will object that the further knowledge they ask you to have - the knowledge that some physical object is in front of you - is an especially significant part of a minimal truthmaker for there being a frog in front of you. Its significance is such (sceptics will continue) that, even if some parts of that minimal truthmaker do not need to be known, you do need knowledge that this particular part of that minimal truthmaker obtains. Maybe you do not need to know that this frog is exactly eleven inches, as against exactly ten inches, distant from you. But you need to know that something physical is in front of you.

So say these sceptics; to whom I have the following reply. Your knowing of there being something physical in front of you is not required as part of knowing that there is a frog there. For example, you might be able to recognise and say, wholly reliably, when a frog is, and when it is not, present - without being similarly sensitive to the more general phenomenon of something's being a physical object. This is not to deny its being probable that your knowing of there being a frog in front of you would in fact include your knowing that there is a physical object there. Is the latter knowledge a required part of your knowing of the frog's presence, though? Would it be present as a matter of conceptual necessity - or only most likely, as a matter of fact?

Knowledge-gradualism is a theory of some forms that knowledge can take. Hence, it allows us to deny that there is any conceptual requirement for the further knowledge to be present. Gradualism permits us to infer that if you do possess the further piece of knowledge, then (other things being equal) your knowledge of the frog's presence is slightly better - more developed, richer - than it need have been. ${ }^{28}$ In other words, gradualism explains away, in non-sceptical

28 The traditional sceptical strategy of requiring further knowledge to be present (if the initial knowledge that $p$ is to exist) coheres with the conception of knowledge that $p$ as an end-point, which is approached only via these many other pieces of knowledge and which cannot be reached until they are traversed. In section 10, that conception was discarded by knowledge-gradualism. And in my (2006b), I explain in more detail - independently of having accepted gradualism - why that conception should be discarded. 
terms, the same aspect of the situation that encourages sceptics to dream - which is to say, the possible lack of the further knowledge described by these sceptics. ${ }^{29}$

Horn2. Suppose that O's not obtaining is not part of a minimal truthmaker for $p$. For example, consider the possibility that you are dreaming that $p$ - without such dreaming entailing $p$ 's being false. ${ }^{30}$ Truthmaker theory allows us to infer that if you are to know that $p$, you need not know of this possibility's not obtaining. The reason is that your having this extra knowledge is not literally part of your knowing that $p$. Insofar as (via $\leftrightarrow \mathrm{H}$ ) knowledge that $p$ just is how-knowledge that $p$, and insofar as (from section 8) how-knowledge that $p$ just is knowledge of some lesser or greater number of parts of a minimal truthmaker for $p$, we derive this result: Knowledge that $p$ need not include knowledge of anything that is not part of a minimal truthmaker for $p$.

Sceptics will resist that inference. They will regard it (on the following grounds) as reflecting a needlessly narrow interpretation of what it is to know:

Some possibilities do not describe situations inconsistent with p's truth. Nevertheless, they can be centrepieces of sceptical challenges to knowledge that $p$. Thus, O's entailing not- $p$ is not necessary to its helping to deprive one of knowledge that $p$. Even if your dreaming that $p$ could coexist with the truth of your belief that $p$, your belief would - if formed via dreaming - be coming into existence inconsistently with its being knowledge that $p$. It would be unjustified, say. ${ }^{31}$

That is a standard sceptical manoeuvre. However, as Heil (1990) has demonstrated, even that sceptical reasoning would not entail your needing to know of your not dreaming. It entails at most your needing not to be dreaming. ${ }^{32}$ And the equivalence (via $\leftrightarrow \mathrm{H}$ ) of knowledge that $p$ with how-knowledge that $p$ supplements Heil's reasoning. Insofar as knowledge of not-O - such as knowledge of one's not dreaming that $p$ - is not knowledge of part of a minimal truthmaker for

29 Sceptics might try 'shrinking' the sceptical possibility, O, so that to know of its not obtaining is ipso facto to know that $p$. (For instance, instead of asking you to know that there is some physical object in front of you, they might require you to know that you are not mistaking a physical object for something other than a frog.) In that case, however, sceptics cannot be advancing the possibility as something further or independent which, if you are to know that $p$, you need to know is not obtaining. Why is that? To the extent that there is 'shrinking', the sceptics' possibility is a description merely of p's not obtaining; in which case, these sceptics cannot be asking you to know of the possibility's not obtaining - with this knowledge being further knowledge you need if you are to know that $p$. For more on this problem confronting some would-be sceptical challenges, see my (2001: 37-40; 2002: 95-7; 2004).

30 Its not entailing not- $p$ is how Stroud (1984: ch. 1) envisages the Cartesian dreaming possibility. For Descartes himself, his dreaming possibility in 'Meditation I' did include his being deceived as to the truth of whichever belief of his was in question. See Haldane and Ross (1911: 145-6).

31 This sceptic's point may be stated in terms of defeaters. A defeater can, as Pollock (1986: 38-9) says, either undercut or rebut. Horn1 concerned $O$ qua rebutting defeater - a possibility bearing upon the truth of the particular belief that p. Horn2's focus is on $\mathrm{O}$ qua undercutting defeater - a possibility bearing upon there being good justification for that belief.

32 No one disputes that there can be related benefits in knowing that one is not dreaming. But it is not obligatory, as a potential knower of $p$, to do whatever is necessary to obtain those possible benefits - extrinsic as they are to the knowing as such that $p$. It is obligatory only when one's goal is to have knowledge that $p$ with those extra benefits. 
$p$, it is literally not knowledge of part of how it is that $p$. So, these sceptics are requiring you to 'expand' or develop the knowledge that $p$ into knowledge of more than $p$ - even of more than how it is that $p$. In particular, it could well be knowledge of how it is known that $p$. And it is not thereby knowledge of how it is that $p$. Hence, by $\leftrightarrow \mathrm{H}$, it is not knowledge that $p$.

Conclusion. From the conjunction of Horn1 and Horn2, sceptics are mistaken when deeming your knowing that not-O to be a necessary condition of your knowing that $p$. Some standard sceptical challenges to the existence of knowledge thus fail.

\section{How not to argue for knowledge-absolutism}

Previous sections have provided some evidence of how epistemologically advantageous it could be to adopt knowledge-gradualism. Why, then, have epistemologists so unhesitatingly accepted knowledge-absolutism? ${ }^{33}$ Based on fragments of arguments I have encountered, here is what seems to be the strongest form of defence underlying the standard assumption of knowledge-absolutism:

(1) Once $p$ is known, there is nothing more - and nothing less - of it to be known by the same person in the same epistemic setting. To know that $p$ is to know the truth of the proposition $p$; and you cannot alter, even slightly, the object of that knowledge without wholly deleting the knowledge that $p$. (Either you lose knowledge altogether, or you replace knowledge that $p$ with knowledge that $q$, where $q \neq p$.) Knowing that $p$ is an all-or-nothing state of affairs. If any different component of the knowledge that $p$ (such as the justification) is altered, even by being improved, again that particular piece of knowledge that $p$ is no more. At best, you gain a new instance of knowledge that $p$. (2) Contrast knowing that $p$ with knowing a person, say. There can be better or worse knowledge of a person - because that kind of object of knowledge has more or less of itself being known at a given time. If more of, or about, the person becomes known, this is not a new instance of knowing that person. The on-going knowledge of the person simply improves. (3) From (1) and (2), although knowledge that $p$ cannot be improved (with more of $p$ becoming known within one piece of knowledge that $p$ ), knowledge of a person can be improved (with more of the person becoming known within one instance of knowing him or her).

But that reasoning overlooks knowledge that p's being how-knowledge that $p$. Given $\leftrightarrow \mathrm{H}$, knowledge that $p$ can - contrary to what (1) claimed - be knowledge of more than simply the proposition $p$. Indeed (depending upon how widespread minimal knowledge actually is), knowledge that $p$ is almost always knowledge of more besides. It generally includes knowledge of further aspects of how it is that $p$ - aspects beyond $p$ as such, most narrowly construed. On such occa-

33 Is it (as Bill Lycan suggested to me) that at least some epistemologists might be relying upon a shallow grammatical point - namely, the inability of the term 'knowing' to admit of comparatives? No one can be said to be knowinger than another in some respect. True; but further explanation is needed. No one can be said, either, to be knowinger than another in some practical respect - an ability. Yet epistemologists routinely agree that knowing-how can be gradational. (Section 15 will comment further on the pertinent linguistic evidence.) 
sions, to know that $p$ is to know more than $p$, to some extent or other. It is to know truths, for instance, other than $p$ - even as part of knowing that $p$. For it is to know some more or less extensive array of aspects of how it is that $p .^{34}$ (Truthmaker theory reinforces that point. We see that knowledge of parts of a minimal truthmaker for $p$ can be knowledge that $p$. And in accord with how many of those parts are being known, there is some correlative degree or quality of knowledge that $p$. Even if not all parts of a minimal truthmaker for $p$ are themselves truthmakers for $p$, they can be minimal truthmakers for a $q$ such that $q$ is an aspect of how it is that $p$; and in knowing that $p$, aspects of how it is that $p$ are what one knows.)

\section{Linguistic evidence}

The (proto-)theory of knowledge being developed here is not intended to stand or fall wholly in response to linguistic evidence. (Unlike contextualism, it is not primarily a theory of knowledge-attributions as such.) Nor has the argument proceeded by repeatedly consulting 'linguistic intuitions'. Other things being equal, though, it would be preferable for the finished theory to cohere with how the word 'know' and its cognates are generally used. Not only would this supply further defeasible and fallible evidence in favour of the theory (at least as a theory of 'our shared ordinary concept of knowledge'); it would facilitate corresponding systemic and theoretical improvements in future ordinary linguistic uses (possibly even modifying 'our shared ordinary concept of knowledge').

And the theory does have some such links with ordinary language. Let us attend to an observation by Douven (2004: 323 n.15). In the midst of an extended critical analysis of contextualism's ability to model various comparative and superlative linguistic constructions involving 'know', he notes that the phrases 'knowing more' and 'knowing most' are 'indisputably part of everyday discourse', while the phrases 'knowing better' and 'knowing best' 'may be somewhat less natural'. Here is how my theory respects those remarks.

(1) My key conceptual move has been to introduce the concept of howknowledge that $p$ - arguing for knowledge that p's being how-knowledge that $p$. And the latter is gradational. How-knowledge that $p$ is knowledge of how it is that

\footnotetext{
34 When does knowing further truths related to $p$ (truths helping to constitute how it is that $p$ ) amount, instead, to knowing some $q$ other than $p$ ? If I know that $p$ poorly today and better tomorrow, I do so by knowing more tomorrow that helps to constitute how it is that $p$. Do I thereby know a different truth tomorrow from what I know today? Other things being equal, I do know a new conjunction of constitutive truths. (I use that description for simplicity. Recall note 16's leaving open the possibility of not all how-knowledge's being only of truths.) How does the new conjunction manage to be knowledge of $p$ - in that respect being like my knowledge today that $p$, which is nonetheless knowledge of a different conjunction of constitutive truths? The answer might emerge from a point made briefly in section 8, paragraph (iii). Within each case (respectively, today's and tomorrow's knowledge, each being ostensibly of $p$ ), there will be some knowledge of how those various other truths are helping to constitute $p$.

35 Importantly, Douven includes, within the intended scope of his analysis, people's uses of those phrases for talking about knowledge that $p$.
} 
p. To have such knowledge is, ipso facto, to have some degree of knowledge of how it is that $p$. Or (in the comparative mode) it is to know more, or it is to know less, of how it is that $p$. Accordingly, some of the linguistic representations it renders applicable constitute a special case of the 'knowing more' (or, equally, 'knowing less') construction which, Douven allows, is clearly an element in ordinary language. He is correct in that assessment. It is natural to speak of knowing more, or knowing less, of what is involved in a friend's being ill, for example: 'I know that she's ill, although I don't know much about it. I don't know many details.' At its core, my theory coheres well with this aspect of ordinary speech.

(2) Then my theory conjoins the gradational dimension described in (1) with an epistemically qualitative assessment: One's knowing more, or knowing less, of how it is that $p$ amounts to one's knowing that $p$ more or less well. Because, by (1), to know that $p$ is to know more or less extensively or fully how it is that $p$, it is to know that $p$ more or less extensively or fully. This, I have urged, is to know that $p$ more or less well. And this construction has the flexibility to cover both precision and vagueness in how we speak and think about knowledge. Precision: It allows us to say how well we know that $p$, perhaps having in mind a specific and good epistemic standard. ('I know that $p$. Actually, I know it well - certainly better than I might have done, and better than I did two days ago.') Vagueness: It allows us to acknowledge epistemic indeterminacy: 'I know that $p$ more or less well roughly, somewhat well. I can't be more specific than that as to how well I know it' (possibly with this admitted vagueness reflecting one's not having in mind any more specific epistemic standard).

Suppose we agree with Douven that people do not often mention how well they know that $p$; generally, they talk just of knowing, or not knowing, that $p$. Even so, this does not entail that they never refer to knowledge qualitatively or gradationally. Nor does it entail that such a way of speaking about knowledge either could or should not ordinarily be used. For a start, that formulation sometimes appears within natural language. ('I know very well that p.' 'As you well know, p.' 'Unfortunately, I only have poor knowledge of that circumstance.' And on it goes.) Admittedly, it is not what people tend to reach for most readily when casually and unreflectively discussing knowledge. It occurs less frequently, usually indicating accompanying thoughtfulness of a kind that results in an acknowledgement of either precision or vagueness (as these were gestured at in the previous paragraph). And that thoughtfulness is often absent when people claim or attribute knowledge. Vagueness: They will not always realise that they know only more or less well that $p$. (Nor might they wish to admit it, when they are aware of it.) Precision: They might not be either able or motivated to ascertain precisely how well they know that $p$. Simply knowing that $p$ - however well this is done will be enough for their perceived purposes. Their discourse will reflect this. It is thereby a simplifying discourse.

By the same token, my theory is not undermined by the fact that 'knows well that p', say, is used much less frequently than the simpler 'knows that p'. From (1): My introduction of the concept of how-knowledge that $p$ is theoretically and 
linguistically apt. From (2): That concept is impliedly a non-absolutist concept of knowledge that $p$. Hence, the latter concept could be absorbed effortlessly into ordinary speech. This would be linguistically apt. It would be theoretically apt, too. Given $\leftrightarrow \mathrm{H}$ and ${ }_{d} \mathrm{~K}$, ordinary language's tendency to speak just of knowing that $p$, rather than of having a more specific degree of knowledge that $p$, or of knowing more or less well that $p$, is at best a conceptual simplification. As I have conceded, maybe distractions within everyday situations encourage the continued use of that form of simplification. But this is not a good reason for epistemological conversations to be inattentive to degrees of knowledge and to knowledge's nonabsolutist dimension. In epistemological settings, we seek to understand some aspects of knowledge which ordinary settings need not even notice, let alone habitually acknowledge. We must therefore be open to the possibility of talking about knowledge in not-obviously-ordinary ways. What we can ask of an epistemologist who does this, however, is that she find an apparent link between overtly epistemological discussions of knowledge and clearly everyday references to it. That is what $\leftrightarrow \mathrm{H}$ and ${ }_{0} \mathrm{~K}$ supply. They show - via the bridging concept of howknowledge - that something which is linguistically everyday ('knows that') is equivalent, at a deeper level of explication, to a disjunction of instances of something that is not linguistically everyday (the instances being 'knows well that', 'knows less well that', and so on).

That transformation does not entail that 'ordinary' talk of knowledge is not ordinary after all (because it is 'implicitly' theoretical). It shows how ordinary talk of knowledge could become less ordinary - rather than being merely supplanted (whenever epistemology is being spoken) by less ordinary talk of knowledge. We also find systemic benefits in adding a non-absolutist dimension to our concept of knowledge, at least so that epistemological discourse becomes more explanatorily powerful. Semantic or pragmatic considerations would not always require us to recognise that non-absolutist dimension in our claims or attributions of knowledge. Nevertheless, it remains conceptually available - which is especially useful in some of epistemology's more technical debates. This is why I have mentioned (to take but two examples) its potential for assisting attempts to understand foundationalism or to withstand sceptical challenges. If we bring this enhanced conceptual framework to bear upon such problems, there is a prospect of making epistemological progress by enriching the conceptual resources that have traditionally been applied to such problems. We would add to our epistemological understanding of knowledge by noticing the gradualist dimension within our concept of knowledge. If we move somewhat beyond ordinary language in doing this, we should not be perturbed. Epistemology is already beyond ordinary language, at least in its more systemic moments - and despite occasional epistemological protestations to the contrary. ${ }^{36}$

36 Chuck Cross, Anne Newstead, and an audience at the 2005 Australasian Association of Philosophy Conference gave me very helpful comments on different drafts of this paper. 


\section{References}

Armstrong, D. M. (2004). Truth and Truthmakers. Cambridge: Cambridge University Press.

Douven, I. (2004). "The Context-Insensitivity of "Knowing More" and "Knowing Better", Canadian Journal of Philosophy 34: 313-26.

Dretske, F. (1970). 'Epistemic Operators', Journal of Philosophy 67: 1007-23.

Elgin, C. Z. (2006). 'From Knowledge to Understanding', in Epistemology Futures, (ed.) S. Hetherington. Oxford: Clarendon Press.

Evans, G. (1982). The Varieties of Reference. Oxford: Clarendon Press.

Foley, R. (1996). 'Knowledge is Accurate and Comprehensive Enough True Belief', in Warrant in Contemporary Epistemology: Essays in Honor of Plantinga's Theory of Knowledge, (ed.) J. L. Kvanvig. Lanham, MD: Rowman \& Littlefield.

Franklin, R. L. (1981). 'Knowledge, Belief and Understanding', Philosophical Quarterly 31: 193-208.

Haldane, E. S. and Ross, G. R. T. (trans.). (1911). The Philosophical Works of Descartes, Vol. I. Cambridge: Cambridge University Press.

Heil, J. (1990). 'Doubts About Skepticism', in Doubting: Contemporary Perspectives on Skepticism, (eds.) M. D. Roth and G. Ross. Dordrecht: Kluwer.

Hetherington, S. (2001). Good Knowledge, Bad Knowledge: On Two Dogmas of Epistemology. Oxford: Clarendon Press.

(2002). 'Fallibilism and Knowing That One Is Not Dreaming', Canadian Journal of Philosophy 32: 83-102.

(2004). 'Shattering a Cartesian Sceptical Dream', Principia 8: 103-17.

(2006a). 'How To Know (That Knowledge-That Is Knowledge-How)', in Epistemology Futures, (ed.) S. Hetherington. Oxford: Clarendon Press.

(2006b). 'Knowledge That Works: A Tale of Two Conceptual Models', in Aspects of Knowing: Epistemological Essays, (ed.) S. Hetherington. Oxford: Elsevier.

Lewis, D. (1996). 'Elusive Knowledge', Australasian Journal of Philosophy 74: 549-67.

Nozick, R. (1981). Philosophical Explanations. Cambridge, Mass.: Harvard University Press.

Pollock, J. (1986). Contemporary Theories of Knowledge. Totowa, NJ: Rowman \& Littlefield.

Rodriguez-Pereyra, G. (2002). Resemblance Nominalism: A Solution to the Problem of Universals. Oxford: Clarendon Press.

Ryle, G. (1949). The Concept of Mind. London: Hutchinson.

Stroud, B. (1984). The Significance of Philosophical Scepticism. Oxford: Clarendon Press.

Williams, M. (2001). Problems of Knowledge: A Critical Introduction to Epistemology. Oxford: Oxford University Press.

Zagzebski, L. (2001). 'Recovering Understanding', in Knowledge, Truth, and Duty: Essays on Epistemic Justification, Responsibility, and Virtue, (ed.) M. Steup. New York: Oxford University Press. 